\title{
EXPERIÊNCIA ESTÉTICA, PRODUÇÃO PARTILHADA DO CONHECIMENTO E PÓS-HUMANISMO: A ARTE MURAL EM TERRA \\ KAINGANG
}

\author{
Magda Vicini ${ }^{1}$ \\ Sergio Bairon ${ }^{2}$
}

Propomos neste artigo uma reflexão e uma ação "outra”, pautadas na interação visual, cultural, antropológica e filosófica que, no decorrer do tempo, foram criadas e absorvidas por meio da convivência com indígenas brasileiros, especificamente neste estudo, com a etnia Kaingang do município de Palmas, Paraná. Essa proposta faz parte de práticas constantes em nossas atuações de pesquisa, quanto ao ser da cultura e suas ausências forçadas a uma invisibilidade em nosso país. Para muitos de nós torna-se mais fácil não tocar neste assunto, pois extrapola a compreensão de que não gostamos de ser vistos como os outros nos veem, mas recusamos a ver o outro/Outro que é igual a mim e diferente de mim. Assim, principalmente a Arte, foi a linguagem geralmente responsável por "representar", na pintura, na gravura, na escultura e em desenhos as "excentricidades" e "novidades" em figuras humanas, plantas, animais, pássaros, comportamentos, etc. do novo mundo ao conhecimento do velho mundo (Beluzzo, 1994). Naquele período, estávamos vivendo (na Europa) a plenitude do Renascimento e do Humanismo. Este Humanismo que nos coloca sempre, pretensiosamente, seres humanos, no centro de tudo. Mas, leia-se, seres humanos brancos, europeus, masculinos e heterossexuais. A filosofia pós-humana (Braidotti, 2013; Ferrando, 2013; 2015) vem questionar este posicionamento central o qual, nós, humanos, nos colocamos, mesmo após termos fracassado como seres responsáveis pela vida, pelo universo, em inúmeras ações como Aushwitz, Hiroshima e Nagasaki, extermínios indígenas, insustentabilidade ambiental, violências diárias contra homossexuais, negros, imigrantes ou o outro/Outro que possa ser diferente da hegemonia europeia. Para Braidotti (2013),

\footnotetext{
${ }^{1}$ Instituto Federal do Paraná, Campus Palmas, Brasil.

${ }^{2}$ Universidade de São Paulo, Brasil.
} 
na visão pós-humanista, deveríamos nos denominar "zoe"3, pois precisamos de uma reconfiguração humana. Neste sentido, seria preciso falar de muitas outras perspectivas de seres humanos, como também de animais, minérios, oceanos, rios, plantas, terras, fontes de água e assim por diante. A produção partilhada do conhecimento compartilha desta necessidade de multiplicar as perspectivas, aproximando-se das noções de perspectivismo e multinaturalismo defendidas por Viveiros de Castro:

Propor um conceito de perspectivismo ameríndio para refigurar um complexo de ideias e práticas cujo potencial de perturbação intelectual ainda não havia sido devidamente apreciado (se é esta a palavra que convém) pelos especialistas, não obstante sua vastíssima difusão no Novo Mundo. (33)

A ele veio se somar o conceito de multinaturalismo, que apresenta o pensamento ameríndio como parceiro de alguns programas filosóficos contemporâneos, seguindo novas bandeiras teóricas como "realismo especulativo" ou da "metafísica experimental". (Viveiros de Castro, 2015: 33)

Portanto, como princípio teórico-filosófico a produção partilhada do conhecimento vem nos oferecer um espaço de democracia, de respeito mútuo pautado na experiência estética de ver, ouvir, sentir, construir e amalgamar a teoria com o saber oral ameríndio.

Com o propósito de desenvolver uma pesquisa sobre as etnias e culturas da cidade de Palmas (PR), optamos por iniciar o primeiro enfoque na Terra Indígena da Aldeia Kaingang. Começamos os primeiros contatos com esta etnia a partir de breves reuniões com a liderança do Cacique e Vice-cacique, Joaílson e Claudecir, assim como algumas reuniões com os professores e diretoria da Escola Sengsõ Táhn Sá, para estabelecer a parceria entre os pesquisadores, a comunidade escolar e indígena. $\mathrm{O}$ estudo está localizado na cidade de Palmas (Paraná), que faz parte da região conhecida historicamente como "Campos de Palmas", na qual as

\footnotetext{
${ }^{3}$ [...] uma proposta de ética pós-humana para um sujeito não mais unitário ou individualista, propõe um senso ampliado de interconexões entre o si e o outro incluindo não humanos e outros possíveis mundos, para remover o obstáculo do individualismo centrado em si mesmo. Sua busca de uma recomposição pós-humana na interação humana não é a mesma que a ligação reativa de vulnerabilidade mas uma ligação afirmativa que localiza o sujeito no fluxo de relações com múltiplos outros. Também sugere ir além das nomenclaturas culturais como processos de hibridismo, nomadismo, diásporas, creolismo, caminhando para uma radicalidade pós-humana, para uma possível não humana ou "zoe" (BRAIDOTTI, 2013: 49-50). "Zoe" as the dynamic, selforganizing structure of life itself (Braidotti, 2006, 211) stands for generative fitality. It is the transversal force that cuts across and reconnects previously segregated species, categories and domains. (2013: 50).
} 
expedições exploratórias chegaram no início do século XIX. A aldeia de Palmas é uma das 17 aldeias Kaingang ${ }^{4}$ no Estado do Paraná e abriga também a Aldeia de Abelardo Luz (SC), com uma população de aproximadamente 755 índios, segundo o Portal Kaingang5. Somente em 27/09/2002 - A FUNAI - Fundação Nacional de Apoio ao Índio - reconhece a terra Kaingang de Palmas, com área de 3.770 hectares e $31 \mathrm{~km}$. Na aldeia Kaingang de Palmas existe a Escola Estadual Indígena Sēngsó Tánh Sá, com aproximadamente 250 alunos desde a Educação Infantil ao Ensino Médio. A Aldeia se localiza a sete quilômetros da cidade de Palmas, facilitando o acesso para realizar a pesquisa, mesmo sendo uma estrada de chão de terra.

Nesses encontros nos quais aconteceram reuniões com professores e líderes indígenas, percebemos o cuidado que esses possuem em conhecer a proposta verdadeira de uma pesquisa, uma vez que afirmam nunca terem acesso às pesquisas realizadas pelas universidades, tanto em relação às investigações realizadas com os indígenas quanto com os professores na escola. ${ }^{6}$ Esta questão sobre a metodologia de pesquisa científica para investigações em terras indígenas será abordada no decorrer deste artigo, a partir das reflexões sobre o perspectivismo ameríndio que elegeu o próprio perspectivismo interespecífico, o multinaturalismo ontológico e a alteridade canibal como os vértices de uma "alterantropologia indígena": "O que obriga-nos a concluir que, a despeito de uma igual ignorância a respeito do outro, o outro do Outro não era exatamente o mesmo que o outro do Mesmo.” (Viveiros de Castro, 2015: 36)

Dessa forma, esta aproximação é de muita importância para o desenvolvimento de nossa proposta metodológica tanto para a Produção Partilhada do Conhecimento, como para o Pós-humanismo e a experiência estética que nos fundamentam.

\footnotetext{
${ }^{4}$ Portal Educacional do Estado do Paraná Secretaria de Estado da Educação do Paraná. Acesso em $15 / 09 / 2018$

${ }^{5}$ Disponível em: $\quad$ http://www.portalkaingang.org/populacao por_estado.htm. Acesso em 15/09/2018.

${ }^{6}$ As informações constadas aqui neste artigo sobre as reuniões com os líderes e os professores da escola, foram colhidas com o consentimento oral desses, uma vez que não possuímos a liberação de ingresso à Terra Indígena Kaingang de Palmas pela Funai e Conselho Nacional de Ética da Plataforma Brasil, mas o processo está tramitando por esses dois órgãos.
} 
Ao realizar as pesquisas preliminares sobre esta Terra Indígena da Aldeia Kaingang de Palmas (PR), encontramos textos e livros de alguns autores bem como a existência de monografias que abordam os Kaingang do sul do Brasil. Desde os etnólogos teuto brasileiros Herbert Baldus (1889-1970) e Curt Nimuendajú (1883-1945), como também o político e pesquisador dos indígenas do Paraná, Telêmaco Borba (1840-1918), o catequizador paranaense Padre Chagas Lima (1757-1832), outros pesquisadores mais contemporâneos como o professor da Universidade de Montreal Robert Crépeau, e dezenas de teses, dissertações e artigos objetivando conhecer a cultura da etnia Kaingang do sul do Brasil.

Em nossa primeira reunião com os professores da Escola Kaingang Sénsgõ, entregamos para o Vice-cacique Claudecir Viri que também é coordenador pedagógico e professor bilíngue desta escola, uma reprodução do artigo de Herbert Baldus, Sprachproben des Kaingang von Palmas ${ }^{7}$ (Dicionário dos Kaingang de Palmas), publicado em 1935 na revista Anthropos: Revue Internationale d'Ethonologie et Linguisthique e também os textos de Roberto Crépeau, sendo que deste último, especialmente o artigo "Mito e Ritual entre os Índios Kaingang do Brasil Meridional” (1997). Ao visualizarem este texto, imediatamente os professores indígenas reconheceram a figura do indígena Kóikáng, o qual Crépeu apresenta em uma citação longa do diálogo entre aquele e o pesquisador Baldus no ano de 1933. Este "reconhecimento" deixa os professores com outro aspecto, que não aquele de não saber sobre o que se fala sobre sua própria etnia mundo afora. O indígena Kóikang é ancestral do Professor de História da escola Séngsõ, professor Sadi, e neste momento, os professores Kaingang presentes na reunião começam diálogos de cumplicidade em relação ao texto.

Sendo o Instituto Federal do Paraná, Campus Palmas sido formado a partir de uma universidade já existente nesta cidade, a Biblioteca é um acervo de monografias sobre as questões indígenas, mas conseguimos encontrar poucos exemplares, sendo os dados mais significativos encontrados na dissertação

\footnotetext{
${ }^{7}$ Revista disponível na Biblioteca Digital Curt Nimuendajú. http://www.etnolinguistica.org. Acesso em setembro/2018.
} 
realizada em 1998, por Lucy Salete Bortolini Nazaro. Nazaro foi professora universitária e atualmente é professora de Educação Básica. $\mathrm{Na}$ dissertação "História e histórias dos Kaingang de Palmas - Paraná. Uma Literatura para a Escola Indígena” (Unicamp/Unicentro, 1998), a pesquisadora realiza entrevistas com alguns anciãos da Aldeia Indígena, relatando suas histórias como proposta metodológica para uma possível utilização dessas histórias na escola, como material didático na então Escola Rural Marechal Cândido Rondon, que possuía alunos indígenas, e situava-se na Aldeia Kaingang. $\mathrm{Na}$ época da pesquisa o espaço geográfico da Aldeia era denominado Posto Indígena Fioravante Esperança. Atualmente se denomina Terra Indígena Kaingang, sendo coordenada pelo Fundação Nacional do Índio - FUNAI - com sede em Chapecó (SC).

Com o objetivo de oferecer o conhecimento científico já escrito sobre esta etnia, estamos entregando pesquisas que encontramos sobre os Kaingang de Palmas, sempre que possível, nos encontros de aproximação com a Escola e Comunidade indígena. Esta atitude de possibilitar o acesso sobre o que se fala sobre o "objeto indígena de pesquisa" nas pesquisas científicas, vem ao encontro do que os pesquisadores Bairon e Lazaneo (2012) argumentam como "reflexividade", o ver-se do sujeito pesquisado, não apenas como objeto de pesquisa, mas como sujeito de pesquisa propondo os indígenas no caso de nossa pesquisa, o poder de decidir, de avaliar e de contribuir sobre o que está sendo apresentado em imagem e texto sobre aquele que em nossa proposta é também sujeito da pesquisa. Em sua dissertação de mestrado ${ }^{8}$, Lazaneo define:

\begin{abstract}
Nesta pesquisa, [...] a definição metodológica de "objeto" é alvo de uma constante reformulação. Destarte, procuraremos empreender um processo no qual fosse possível elaborar estratégias de desenvolvimento de pesquisa com uma comunidade em que esta, não mais atuando como "objeto", participe como sujeito da partilha do processo de produção de conhecimento, seja através de propostas que envolvem um grande número de participantes das respectivas comunidades ou, pormenorizadamente, através do trabalho específico de alguns de seus interlocutores (Lazaneo, 2012:36).
\end{abstract}

O compartilhamento de ideias abre para uma pesquisa dialógica e não para uma pesquisa na qual somente o ser científico, a partir de sua mediação, de sua tradução como sujeito culturalmente e individualmente diferente de outro sujeito

\footnotetext{
${ }^{8}$ LAZANEO, Caio de Salvi. Produção Partilhada do Conhecimento: Uma experiência com as comunidades indígenas Xavante e Karajás. Dissertação de Mestrado - Diversitas - USP, 2012.
} 
que é pesquisado, tenha mais valor do que o dito "objeto de pesquisa", que é Outro/outro ser humano cultural e individual, mas sim, dialogando sobre o que se escreve, o que se reflete, o que se mostra como imagem do Outro/outro, que supostamente é igual a mim, mas diferente de mim. Nesse aspecto, o conceito de inclusivismo situado, adotado pela filósofa e professora da Universidade de Nova Iorque, Francesca Ferrando (2012; 2016), poderá nos auxiliar a pensar e agir no sentido de não se resolver as transformações simbólicas humanas em um coletivo hegemônico, sem respeitar as características individuais de um grupo étnico, de um sujeito inserido em uma coletividade.

A pesquisadora Ferrando (2013), propõe um olhar sobre a diversidade humana. Para ela, o pós-humano pretende desconstruir o humano, no sentido de revisitar a teoria do especismo, ou seja, o privilégio de alguns em detrimentos de outros: principalmente o privilégio do ser humano diante de todas as outras espécies. Segundo Ferrando (2013), o termo pós-humano é rizomático, permite diversas definições dentro do mesmo movimento. Ainda segundo a autora, o póshumano reflete sobre o significado amplo do progresso tecnológico, mas não pode se restringir a isso, quando se tem populações no mundo ainda preocupadas em sobreviver; se não houvesse esse tipo de preocupação, este se restringiria ao aspecto técnico científico e classista (Ferrando, 2016:24), o que se distancia da concepção do pós-humanismo. Segundo a filósofa,

Para orientar a sua própria perspectiva para esse efeito, o pós-humanismo deve estar enraizado em um extenso estudo crítico sobre o que significa ser/ humano, oferecendo uma fronteira (terminus a quo) estratégica a partir do qual se possa imaginar uma próxima pós-humanidade que exponha em discussão o discurso tradicional de poder "neutro" e vir a ser incluído para um número crescente de subjetividades localizadas. (Ferrando, 2013:s/p)

Outro argumento utilizado nesta pesquisa é o sentido de representação de imagens nas produções artísticas sobre os indígenas ao longo da história de nosso país, como por exemplo, as pinturas de Albert van der Eckhout (1610-1666). Questionamos a maneira pela qual há representações de etnias brasileiras ou afrobrasileiras nas pinturas, ou seja, indígenas e negros, mediadas ou traduzidas pela estética colonizadora europeia, em relação à realidade de uma imagem desses grupos étnicos naquela mesma época. Nesse mesmo sentido, em pinturas atuais, como o indígena se vê sendo representado por artistas que não conhecem seu 
cotidiano ou sua maneira de ser no mundo? Essa questão nos instiga a buscar respostas a partir desta pesquisa, de uma possível representação a ser realizada pelos próprios indígenas, propondo que eles criem e realizem um mural sobre sua própria etnia como produção partilhada do conhecimento, bem como a produção de vídeos e textos sobre os Kaingang de Palmas (PR).

Nessa visão, questionamos a ausência de experiência estética entre o sujeito artista e o sujeito outro representado nas imagens sobre os indígenas produzidas por artistas europeus ou até mesmo brasileiros, nas quais a qualidade de experiência estética acontece somente com o artista no momento de criação e execução da pintura, e o "objeto de pesquisa" ou o outro representado é relegado a segundo plano, a favor de uma estética da arte dominante. Nos propomos assim, a pensar qual o possível desvelar sobre a cultura e vivência estética dos índios Kaingang da cidade de Palmas (PR), realizando uma pintura mural coletiva fundamentada na produção partilhada do conhecimento e na filosofia póshumana? Qual o sentido de representação e auto-apresentação que pode "vir a ser”, partindo-se de uma reflexividade e produção estética a partir do olhar e da vivência de uma cultura tradicional indígena que tem sido representada em diversas formas de imagem pictórica, fotográfica ou textual por um sujeito que não compartilha de uma mesma experiência estética cotidiana?

A pesquisadora e artista Vicini, junto com colegas professores ${ }^{9}$ do IFPR Campus Palmas realizou um projeto de pesquisa e extensão no Instituto Federal do Paraná, Campus Palmas, finalizado em dezembro de 2016, no qual foi desenvolvido um mural em 10 painéis somando a dimensão de 5,50 x 4,40m, denominado "Etnias e Culturas Formadoras de Palmas (PR). Nesse projeto, a grande dúvida pairou sobre a questão ideológica dos muralistas mexicanos: uma arte social que buscou distanciar-se da modernização capitalista (artesanato/arte; cultura popular/cultura culta) e enfatizar as representações culturais populares, regidas por uma necessidade de integração nacional. De que maneira essa revisitação ao muralismo poderia se aproximar das questões contemporâneas de experiência estética da arte, considerando-a como inclusão e integração cultural?

\footnotetext{
${ }^{9}$ Projeto realizado com os professores: Douglas Colombelli Parra Sanches, Luiz Ney Todero, Neuza Fonseca e Tiago Scalvenzi Sául.
} 
De que maneira artistas brasileiros trabalham o muralismo a partir do tema da diversidade cultural na atualidade? Como se estabelece uma reflexividade entre pesquisador artista e objeto de pesquisa na elaboração de uma pintura mural? Como aponta Lazaneo (2017), expondo sobre a produção partilhada do conhecimento, e que apontamos como possibilidade de relação com o póshumanismo e o conceito de inclusivismo situado:

\begin{abstract}
Poderíamos de algum modo refletir que, em Produção Partilhada, o pesquisador também é um "nativo" para o "nativo", e o habitualmente considerado "nativo" é também ele um "pesquisador". [...] Esta premissa porém, não fundamenta-se nem sob uma ideia de homogeneização do conhecimento (supostamente entre o pesquisador e o nativo, um binômio insuficiente como vimos) e nem, tampouco, de exclusão da diferença mas, de outro modo, da conjugação dos sentidos, afetos e diferentes formas possíveis de formação do conhecimento inauguradas pelo encontro. (Lazaneo, 2017:117)
\end{abstract}

Ao olharmos as representações em pintura das nações nativas brasileiras, no decorrer de cinco séculos de colonização, sugere-se uma breve observação sobre os primeiros artistas que utilizaram como tema de suas obras os indígenas e os negros, no sentido de questionar o conceito de "representação" e "reflexividade" dessas culturas. Albert van der Eckhout (1610-1666), artista que esteve na região nordeste do país a convite de Maurício de Nassau, governadorgeral do Brasil holandês, realizou centenas de desenhos e pinturas que conceituam a visão eurocêntrica em suas obras (Figura 1 e 2). 


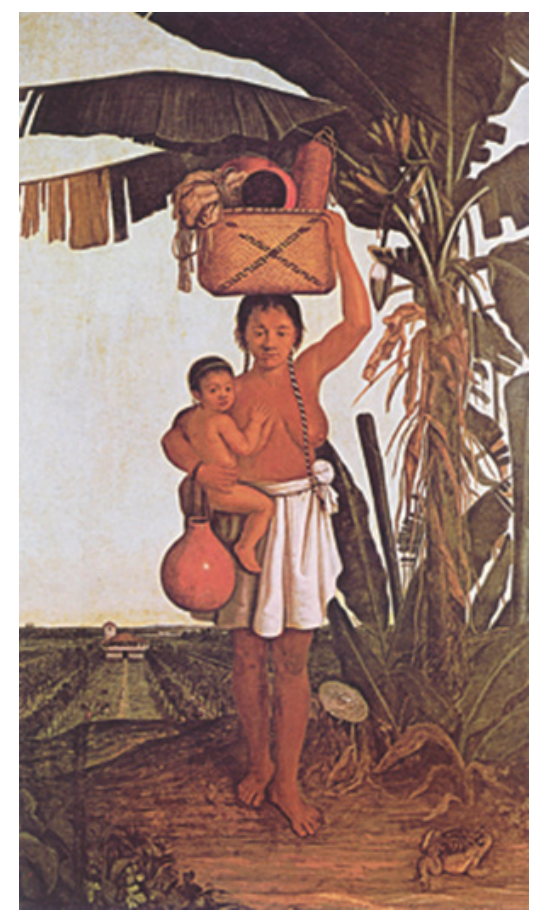

Figura 1 - Índia Tupi - Eckout - $1641-274.00 \mathrm{~cm}$ x $163.00 \mathrm{~cm}$ - Acervo Nationalmuseet (Copenhague, Dinamarca)

Fonte: $\underline{\text { http://enciclopedia.itaucultural.org.br/pessoa10299/albert-eckhout }}$

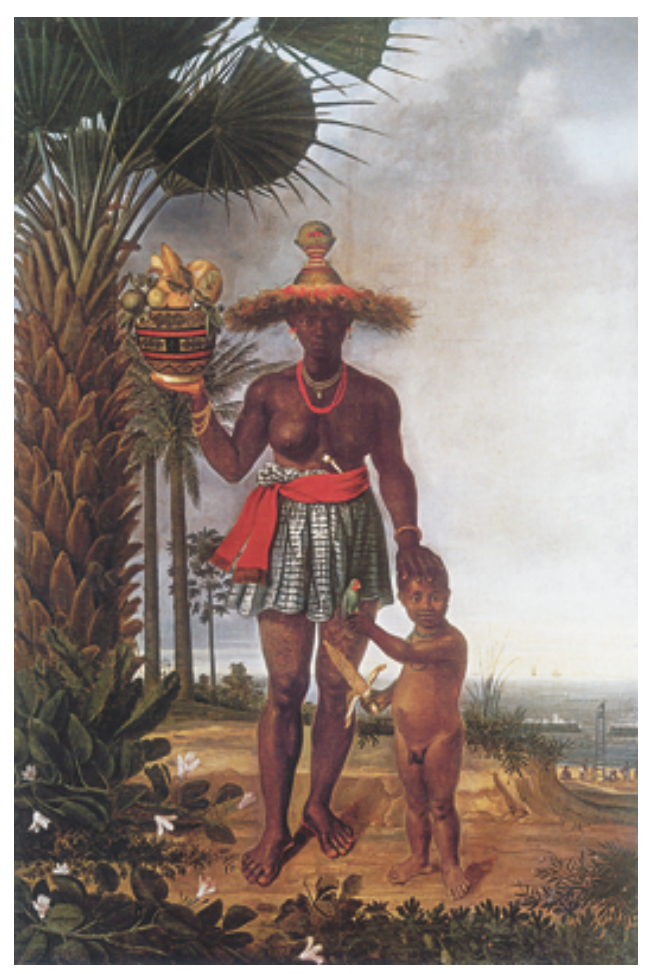

Figura 2 - Mulher Africana - Eckout - 1641 -Dimensões $267.00 \mathrm{~cm}$ x $178.00 \mathrm{~cm}$ Acervo Nationalmuseet (Copenhague, Dinamarca)

Fonte: http://enciclopedia.itaucultural.org.br/pessoa10299/albert-eckhout

Iluminuras, Porto Alegre, v. 20, n. 50, p. 227-254, julho, 2019. 
Conforme visualizado nas imagens, é a visão de um artista europeu sobre os nativos brasileiros, na qual as influências da pintura holandesa de gênero, bem como a estética idealista do corpo humano advinda do Renascimento, Barroco e Maneirismo adquirem força de representação na pintura. Conforme Beluzzo (1994) analisa uma série de quatro obras pintadas por Eckout: Homem Tapuia (1643) e Mulher Tapuia (1641); Homem Tupi (1643) e Mulher Tupi (1641); Homem Mulato (s.d.) e Mulher Mameluca (1641) e Homem Negro e Mulher Negra, ambos de 1664.

Visualizamos que a representação dos nativos brasileiros nessas obras segue um ideal de beleza e estética europeus, distante da aproximação e reflexividade da cultura indígena brasileira, uma vez que a interação entre artista e nativos se daria de forma distanciada e não dialógica, cujo papel do artista era "retratar", a seu modo de ver, o novo mundo descoberto pelos europeus. Cabe-nos lembrar que este projeto de pesquisa não se pretende fundamentar os aspectos da estética da arte, mas sim, arte como experiência estética a partir da vivência entre pesquisadora/conhecimento científico e comunidade indígena/conhecimento tradicional.

Os murais, tendo sua origem na arte mexicana, foram referências para outras manifestações ideológicas, contestadoras, como também decorativas. Os murais tiveram uma força política e uma atuação reveladora de conflito religioso na Europa, Irlanda do Norte, quando protestantes e católicos ou na linguagem irlandesa, os "lealistas" (protestantes) e os "republicanos" (católicos), comunicavam-se a partir dos murais realizados em muros, paredes de casas e empresas. Segundo Gerry Adams, presidente dos "Sinn Féin" (CatólicosRepublicanos) no Documentário "Arte do Conflito: murais na Irlanda"10 (2012) de Valeri Vaughn, produtor americano, eles utilizaram a arte na linguagem do mural como forma de expressar a violência e a repressão, pois eram censurados pela televisão; os jornais de ambos grupos eram invadidos entre si e por policiais, e o mural funcionava como uma forma de comunicação com o mundo e entre eles próprios (Figura 3).

${ }^{10}$ Disponível no site Netflix. Acesso em novembro de 2016. 


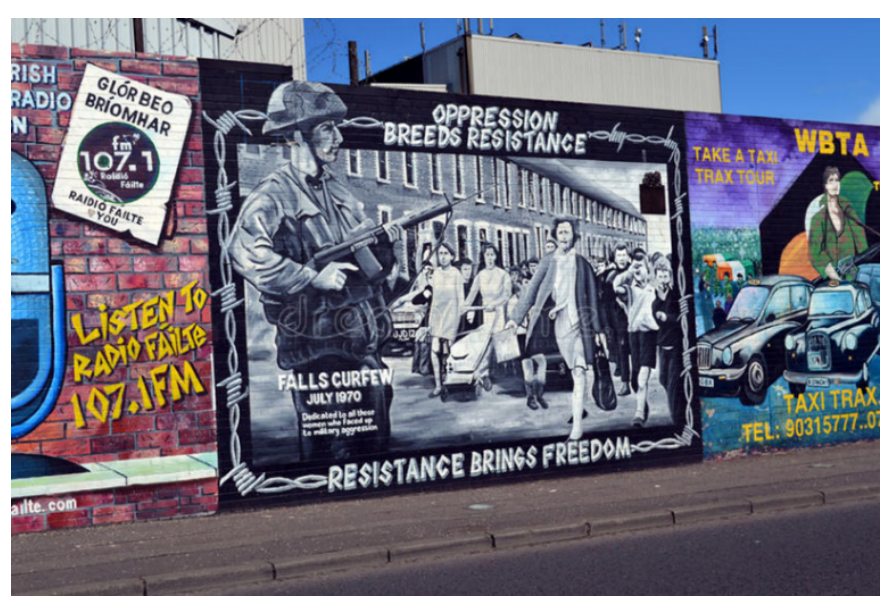

Figura 3 - Mural "Resistence - Freedom" - Belfast, Irlanda - Autor Desconhecido Fonte: https://br.pinterest.com/pin/280419514271190993/?1p=true

No ano de 2010, A Fundação Miró de Barcelona (Espanha), protagonizou a exposição Murals: Práctiques Murals Contemporánies, trazendo uma eclética produção contemporânea de murais de artistas dos continentes Africano, Europeu, Asiático e Americano. Dentre eles, participaram da exposição a Cooperativa Feminina de Djajibiné Gandega "Djida", que é uma etnia subsaariana da Mauritânia (África), cujas mulheres artistas definem sua arte como uma pintura mural doméstica que mantém vivas antigas tradições sociais e culturais, nas quais as mulheres se encarregam desta prática de seus ancestrais soninke. Trata-se de uma atividade coletiva desse povo dedicada aos recém-casados que iniciam uma nova família. Os murais são realizados nos muros das casas e são produzidos com terra, pintados com os dedos, utilizando como material de pintura uma pasta colorida misturada com terra moída, água, pigmentos e ingredientes vegetais aglutinantes, simbolizando uma oferenda como retorno ao que a terra tem dado para fazer a pintura (Catálogo da Exposição, 2010:134). Percebe-se, na metodologia de criação da Cooperativa Feminina, um fazer como experiência estética a partir de um significado cultural implícito, carregado de simbologia em toda a forma e conteúdo refletida no mural - os próprios nativos são os produtores de suas imagens sígnicas ou simbólicas. Percebe-se aí uma experiência estética no sentido deweyneano, na qual o fazer está relacionado intimamente com o ambiente no qual está sendo produzido, e tem uma relação intelectual, transcendental, emocional e estética. 
No México, o artista Santos della Torre, artista Huichol (de Wixarika, México), desconhecido do mundo, cuja obra está no metrô de Paris, foi apresentado no documentário "Eco de la montana" Nicolás Echevarría (1947), lançado em 2015, que relata em seus murais toda a cosmologia do povo Huichol, em grandes dimensões. Em suas obras, della Torre desenha e pinta, refletindo conscientemente e esteticamente sobre símbolos e signos da cosmologia nativa. É um trabalho solitário que às vezes tem a presença de alguns de seus familiares, no qual se apresenta uma profunda relação de experiência estética entre a cultura representada, a obra artística finalizada e o artista que a produziu (Documentário, 2015). É preciso levar em conta que, no caso da Cooperativa Feminina africana, as próprias mulheres foram a Barcelona, ao Museu Miró realizar a pintura mural levando sua presença e cultura, já no caso do artista della Torre, a sua pintura foi levada para ser colocada na estação de metrô de Paris, e sua frustração como artista e ser cultural foi documentada pelo Diretor Echeverría (autor do documentário sobre este artista), sobre o mural de Paris:

\begin{abstract}
Eu não estava lá. Iam me convidar mas não me convidaram. Em vez de ir à França, fui à minha lavoura fazer a colheita. Aliás, o mural não foi bem instalado porque não fui eu que montei" (o mural de Santos de la Torre, artista Huichol, que foi colocado no Metro Palais-Royal de Paris, $1997^{12}$ ). [...] Eu nunca me esqueci. Não me deixaram aleijado nem ferido, mas na alma sim. Assim foi. (De la Torre, 2014 apud Documentário, 2015)
\end{abstract}

Analisamos que o ser da cultura não pôde estar apresentando sua própria cultura elaborada por uma vivência secular de sua própria arte e cultura, da mesma forma que aos indígenas, quando pesquisados, não tem acesso ao conhecimento que foi elaborado a partir deles mesmos, diminuindo-os enquanto sujeitos que produzem uma cultura. Ao mesmo tempo, vê-se o reconhecimento do brasileiro Eduardo Kobra $^{13}$ (1976), grafiteiro e muralista, tendo sua obra reconhecida pelo mundo, em seus murais de grandes dimensões, cujos temas envolvem, por exemplo, a história de São Paulo, nos "Muros da Memória" (2012); e as pinturas de indígenas nos três mil metros de pintura no Rio de janeiro, denominado de "Etnias" (2014) entre outros murais. Kobra pintou "Muros da

\footnotetext{
${ }^{11}$ Disponível no site Netflix. Eco de la Montana. Acesso em 15/06/2017.

${ }^{12}$ Parênteses nosso.

${ }^{13}$ Site do artista Eduardo Kobra. Disponível em: http://eduardokobra.com/. Acesso em 5/5/2017.
} 
memória" a partir de imagens fotográficas provenientes da década de 1950 de São Paulo, sendo que o artista, nascido em 1976, não vivenciou esse período paulista. Da mesma forma, as imagens que Kobra pintou no mural "Etnias" dos diversos povos nativos do mundo, no período das Olimpíadas no Rio de Janeiro (2014) não resultaram do contato ou vivência com esses grupos. Que tipo de representação ou experiência estética sem uma forma de compartilhamento pode produzir uma obra sobre esses grupos/outros representados nas pinturas?

Pode-se citar também a ampla utilização do termo "mural", em diversas ações desenvolvidas de pintura em grandes dimensões como dos artistas curitibanos Rimon Guimarães e Zéh Palito, que ocorreu em Damasco, na Síria, como possibilidade de mudar o olhar da constante situação de guerra na qual vive esse país; ${ }^{14} \mathrm{e}$, assim, centenas de propostas ecológicas, sociais, educacionais e políticas podem ser vistas como objetivos para criação de murais ao redor do mundo, ${ }^{15}$ com diferentes objetivos e justificativas. Percebendo a produção de mural contemporânea, haveria um sentido idealista, cultural, estético e pessoal que leva à produção desses murais. De que maneira pode-se pensar a produção mural a partir de uma abordagem de Produção Partilhada do Conhecimento, do pós-humanismo crítico e suas metodologias?

Ao falarmos sobre etnias indígenas acreditamos ser relevante abordarmos o conceito de "cultura", pois esta pode significar uma fragmentação, limitação, coletividade, unicidade, pluralidade ou universalização, dependendo do espaço geográfico, da área de conhecimento e do posicionamento ideológico que se adota, tendo em vista que ela abrange aspectos simbólicos nas diferentes formações humanas, na natureza humana e natureza amplamente considerada (animais, minerais, vegetais, planetas, etc). Ao adotar uma postura pós-humana crítica, o conceito de cultura ainda precisa ser amplamente discutido, pois, como

\footnotetext{
${ }^{14}$ A pintura urbana tem $270 \mathrm{~m}^{2}$ e é resultado do coletivo de arte contemporânea Conexus. Com curadoria da gaúcha Sheila Zago, o grupo de artistas viaja o mundo promovendo intervenções em locais em que grande parte da população encontra-se vulnerável.Disponível em: http://www.huffpostbrasil.com/2017/05/22/o-maior-mural-de-grafite-ja-feito-na-siria-e-obra-deartistas-br a 22103525/. Acesso em Junbo/2017.

${ }^{15}$ A arquiteta portuguesa Lara Seixo Rodrigues, de 37 anos, criou em 2012 o projeto Lata 65, que leva idosos para as ruas das cidades, para aprenderem técnicas de intervenção urbana e grafitarem paredes e muros. A iniciativa quer mostrar que a idade é apenas um número. Disponível em: http://www.huffpostbrasil.com/2017/01/25/o-projeto-portugues-que-coloca-idosos-para-grafitaras-cidades_a 21698864/?utm hp ref=br-grafite. Acesso em junho/2017.
} 
será apresentado, o posicionamento pós-humano se distingue do posicionamento humanista, propondo a descentralização do homem em relação ao meio ambiente, seu universo vivido, seu umwelt.

A noção de cultura está geralmente implícita à de identidade do "ser humano" e suas relações com o modo de se relacionar entre si e seus objetos contemporâneos, sua subjetividade, seu contexto, suas crenças, no sentido de que há um sujeito em determinado espaço que produz sinais e símbolos (CASSIRRER, 2005:48-49) para se comunicar, para se proteger, para se alimentar e se expressar em diversas formas. Como pensar o conceito de cultura para a póshumanidade? Cultura esta que na atualidade pode ser observada virtualmente a qualquer hora, em diferentes países e povos, neste mundo conectado pela internet. Isso pode promover transformações culturais, bem como inserções, diferenciações e ampliações culturais também na arte. Tanto para o pesquisador de arte brasileiro Moacir dos Anjos (2005), como para Baurrioud (2014), o espaço da globalização abriu o caminho para a diversidade na arte, a partir da exposição "Os Mágicos da Terra" (1989), que ocorreu no Centro Georges Pompidou, em Paris, e pode ter marcado este olhar para a diversidade cultural e artística de todos os continentes da terra. Ambos os autores indicam esse momento crucial para a compreensão de uma visão de mundo globalizado. Mas essa percepção pós-moderna multicultural e relativista, sob o olhar da concepção de Baurrioud (2014:32) de analisar a arte a partir do contexto cultural, não seria também uma forma de normatizar a leitura da arte, priorizando os pertencimentos culturais?

\begin{abstract}
Cada qual se vê assim situado, matriculado, pregado em seu local de enunciação, encerrado na tradição de que supostamente provém. "De onde você está falando?", pergunta a crítica, como se o ser humano sempre permanecesse em um lugar, um só lugar, e dispusesse, para se expressar, de um único tom de voz e de uma única língua. Está aí o ponto cego da teoria pós-colonial aplicada à arte, que concebe o indivíduo como definitivamente rotulado com suas raízes locais, étnicas ou culturais. Ela faz, assim, o jogo do poder, pois o que este deseja intensamente são sujeitos que enunciam eles próprios sua identidade, facilitando sua classificação estatística. [...] a fim de distribuir melhor seus produtos. (BOURRIAUD, 2011:32)
\end{abstract}

A partir dessa reflexão de Bourriaud (2011), questiona-se: até que ponto a definição de cultura se relaciona com o contexto da arte na atualidade? Ao se utilizar imagens da cultura, de que maneira ela possui reflexividade em relação 
àqueles que produzem essa cultura? Desde a metade do século $\mathrm{XX}$, a crítica tem aberto seus olhares e reflexões sobre o multiculturalismo, abrindo o sistema das artes para as "margens" do globo terrestre para artistas latinos, africanos, asiáticos, e outros, descentralizados da Europa e Estados Unidos (BARRET, 2014). Essas "outras" artes e espaços que a Modernidade excluiu tornam-se o motor de muitas produções estéticas da Pós-modernidade, a partir dos anos 1980.

Pretendemos relacionar em nossa pesquisa a estética que, em sua tradução proveniente do grego, "Aisthetikós", significa o que é percebido pelos sentidos; e "Aísthesis", do latim, sensação, sensibilidade, neste projeto torna-se relevante, pois é na essência da "produção" de algo que se desenvolve a experiência que envolve os sentidos, e não apenas no fruir dessa produção de forma coletiva ou individual. Essa experiência estética do ser/fazer/sentir/existir chama a atenção para o modo pelo qual as culturas são faladas/expostas/exploradas/ pela arte em suas diferentes linguagens: o texto, a pintura, o vídeo e outras. Como desvelar essa experiência estética, a partir da vivência da etnia Kaingang de Palmas, nas linguagens de textos, de fotografias, de pinturas e de imagens em vídeo?

Experiência estética que se concebe a partir de Dewey (1980), Heidegger (2000) e de Gadamer (1999). Inicialmente em Dewey:

\begin{abstract}
Tentei mostrar que o estético [...] é o desenvolvimento clarificado e intensificado de traços que pertencem a toda experiência normalmente completa. A concepção de experiência consciente enquanto relação percebida entre o fazer e o padecer torna-nos aptos para a compreensão da conexão que a arte, enquanto produção e percepção, e a apreciação, enquanto gozo, mantêm uma relação com a outra, porque todo o fazer artístico envolve um fazer com o corpo, com instrumentos, produzindo algo visível. (Dewey, 1980:98)
\end{abstract}

Para Dewey (1980), todo o fazer pode significar uma experiência estética, desde que percebida conscientemente em seu caráter intelectual, emocional e estético, e isso pode ser realizado cotidianamente, não apenas no que se denomina arte que está nos museus, a obra do artista. É a obra que é produzida em um espaço geográfico qualquer, que produz a experiência estética tanto daquele que a produz como daquele que venha a contemplar essa obra, a percepção do padecer, deixar-se envolver por essa experiência, amadurecer esta experiência. Nesse mesmo sentido, Joseph Beuys (Kuoni, 1993) proclamava nos anos 1970, que 
"todos somos artistas" e que até o ato de descascar uma batata pode ser uma obra artística. $\mathrm{O}$ importante seria a forma pela qual você promove o sentido do ato que venha a desenvolver em qualquer trabalho diário, é o processo entre o ser e o experienciado.

Para Gadamer (1990), ao construir uma relação entre o jogo e a obra de arte, ele propõe que da mesma forma que no processo do jogo, entre os jogadores acontece uma representação, há igualmente uma representação entre a obra de arte e o espectador que irá frui-la, e acontece nessa relação um despojamento diante da obra de arte (jogo), mesmo que inconscientemente, proporcionando a quem está diante dela um encontro com algo que não é de seu domínio. Essa vivência, ou melhor, "dasein" (estar contínuo do ser), é a experiência estética promovida pela obra de arte.

Essas propostas de experiência estética se relacionam a este projeto no sentido do desvelar heideggeriano (2000) segundo o qual a desocultação pode ser a dissimulação ou engano.

O tranquilizante é, no fundo, não tranquilizante; é um abismo de inquietação. [...] Mas esta verdade é não-verdade, não no sentido de ser falsa, mas sim que a verdade nunca é ela mesma, mas sim representada dialeticamente, sempre também o seu contrário. (Heidegger, 2000:43)

Desvelar o humano pode estar relacionado com a concepção filosófica do pós-humanismo, a qual pretendemos dar uma breve introdução, uma explanação epistemológica de vertentes existentes neste movimento cultural e filosófico (Sorgner; Gimm, 2012:12). O termo pós-humanismo foi apresentado pela primeira vez pelo professor e escritor da Universidade de Princenton (EUA), Ihab Hassan em seu artigo "Prometheus as performer: toward a posthumanist culture?" (1977). No artigo, Hassan justifica o uso da palavra pós-humanismo, anunciando que

É preciso entender que a forma humana [...] pode estar mudando radicalmente e, portanto, deve ser revisitada. Precisamos entender que quinhentos anos de humanismo pode estar chegando ao fim, como o humanismo se transforma em algo que devemos desesperadamente chamar pós-humanismo. (Hassan, 1977:212, in Sorgner e Grimm, 2014:74) 
Para Franssen (in Sorgner e Grimm, 2014:74), Hassan apresenta seu conceito a partir do mito de Prometeu, representando o espelho da ambiguidade humana, como ladrão e herói, como define Hassan

Prometheus é ele mesmo a figura de uma consciência falha lutando para superar [...] divisões [...]. Com relação ao pós-humanismo em si, o aspecto mais relevante das preocupações dialéticas desse mito refere-se a: Imaginação e Ciência, Mito e Tecnologia, Terra e Céu. Uma vez que ele retira o conhecimento dos deuses e divide com os humanos, fica "entre", compartilha, dissolve-se a divisão humanista: homem/máquina, subjetivo/objetivo, ciência/cultura, e o antropocentrismo. (Hassan apud Franssen in Sorgner e Grimm, 2014:74)

Há que se considerar que uma das primeiras definições sobre o póshumanismo ${ }^{16}$ pesquisa a relação do ser humano com as novas tecnologias tanto no sentido das próteses que se adaptam ao corpo humano, a produção de seres com inteligência além da capacidade humana, robôs, como também no sentido de melhoria genética e produção de sentido e significados dessas tecnologias para a subjetividade humana.

O pós-humanismo se apresenta como descendente do pós-modernismo, e nesse sentido, acredita na defesa da diversidade e da valorização do outro/Outro, como forma de alteridade e inclusão (Ferrando, 2013). O caráter que chama a atenção no conceito de pós-humanismo para esta pesquisa está ancorado na visão das filósofas italianas Francesca Ferrando (2012, 2013) e Braidotti (2013).

Para a filósofa italiana Ferrando (2013), o sentido do pós-humanismo pretende ir além dessa relação entre seres humanos e tecnologias, propondo uma forma de rever posicionamentos ocidentais e fragmentários que foram as práticas do humanismo.

Pós-humanismo reflete sobre termos de sustentabilidade humana, mas não ignora o significado de sobrevivência humana: não rejeitando direitos humanos ou individuais, pós-humanismo é diferente de anti-humanismo. A semântica dos dois termos apresenta outra discrepância: mais do que um anti, Pós-humanismo é um pós/meta/trans. Na tentativa de evitar polarizações simplistas, pós-humanismo não negligencia meta-narrativas ou metafísica, mas reconhece o seu uso instrumental para investigações intelectuais e existenciais. [...] O pós-humanismo oferece uma revisitação do ser como imanência transcendental, interrompendo uma das divisões fundadoras do pensamento ocidental, entre transcendência e imanência, que simbolicamente

\footnotetext{
${ }^{16}$ Ver também publicação brasileira do Professor Dr. Francisco Rüdiger. Breve história do póshumanismo: Elementos de genealogia e criticismo. E-compós.Abril/2007.
}

Iluminuras, Porto Alegre, v. 20, n. 50, p. 227-254, julho, 2019. 
se refere a todos os outros tradicionais dualismos, tais como: a mente/corpo, sujeito/objeto, eu/outro, masculino/feminino, humano/ animal - alien - robô. (Ferrando, 2013:10-11) ${ }^{17}$

Para a professora da Universidade de Ultrecht (Holanda), Rosi Braidotti (2013:12), seu interesse no pós-humanismo é devido ao fato de estar frustrada com o humano, demasiado humano que limita nossas possibilidades intensas e criativas a nível individual e coletivo. Braidotti (2013:37) acredita nas possibilidades e limitações que podem originar um posicionamento positivo e próativo em relação aos destinos de nosso mundo, tendo como legado o póscolonialismo, o pós-estruturalismo e o anti-humanismo (como antecedente ao póshumano), acreditando que o pós-humanismo crítico pode levar a uma compreensão maior sobre o humano mais complexo e subjetivo (Braidotti, 2013:26).

\begin{abstract}
A crise do Humanismo significa que as demais estruturas humanísticas do sujeito moderno surgem com força total na pós-modernidade. É um fato histórico que os grandes movimentos emancipatórios da pós-modernidade são conduzidos e alimentados pelos "outros" ressurgentes: movimentos dos direitos da mulher; os movimentos anti-racistas e de descolonização; os movimentos anti-nucleares são as vozes das Outras estruturas de modernidade. Eles inevitavelmente marcam a crise do antigo "centro" humanista ou a posição do sujeito dominante e não são meramente antihumanistas, mas movem-se além dele em direção a uma inovação total, o projeto pós humano. (Braidotti, 2013:37)
\end{abstract}

A noção de pós-humanismo não se restringe à relação entre homem e tecnologia, mas sim, reflete sobre as alteridades excluídas e fragmentadas a favor de um ser humano dominante branco, europeu, rico, heterossexual, homogeneizando culturas que sobrevivem à margem da classe dominante. Alicerçados no pós-humanismo crítico, visualizamos a produção do mural real ou virtual, no sentido de compreender as práticas culturais como experiência estética explorando a pluralidade de uma cultura a partir da colaboração individual de cada participante da proposta, como defende o inclusivismo situado, da filósofa Francesca Ferrando (2013).

\footnotetext{
17 Ferrando, F. (2012).Towards a Posthumanist Methodology. A Statement. In: Narrating Posthumanism. Frame, 25.1, May 2012, Utrecht University, Utrecht, 9-18. ISSN: 0924-7750. http://www.academia.edu/1243762/TOWARDS_A_POSTHUMANIST_METHODOLOGY_A_St atement. Acesso em 2014.
} 
O "inclusivismo situado" significa a prática pós-humana da constante reformulação simbólica humana, que se propõe não resolver no coletivo a perspectiva individual, mas que a reconheça em um pluralismo situado e não disciplinável. O risco dessa prática seria uma universalização acrítica e exclusiva, que impossibilitaria este conceito. (Ferrando, 2013:s/p)

Como desenvolvido nos projetos de Lazaneo (2012, 2017), os vídeos produzidos e criados pelos índios Bororo e Xavante, acreditamos que a metodologia utilizada para o desenvolvimento de seus projetos pode ter uma relação com o conceito de inclusivismo situado proposto pelo pós-humanismo crítico, partindo da metodologia de produção partilhada do conhecimento e a relação dialógica entre os grupos étnicos e os próprios pesquisadores envolvidos. Essa hipótese relacional entre esses conceitos é o que pretendemos investigar nesse projeto de pesquisa.

Para situarmos a concepção pós-humana, a filósofa Braidotti (2013) aponta para a existência de três vertentes no pós-humanismo:

[...] a primeira surge da filosofia moral e desenvolve uma forma reativa de pós-humanismo; a segunda, provém dos estudos da ciência e tecnologias com uma forma analítica de pós-humanismo; e a terceira, vem de minha própria tradição anti-humanista pela subjetividade que propõe o pós-humanismo crítico. (Braidotti, 2013:38)

Para Braidotti (2013), a aproximação reativa do pós-humanismo advém conceitualmente e politicamente do pensamento liberal de autores como Marta Nussbaum $(1999,2010)$. Nussbaum cria uma defesa contemporânea completa do Humanismo como garantia para a Democracia, a liberdade e a dignidade, rejeitando a crise no Humanismo Europeu e muito menos a possibilidade de seu declínio histórico. A autora rejeita as percepções radicais dos últimos trinta anos, realizadas pelos anti-humanistas como Foucault, Deleuze e Iragaray (Braidotti, 2013:39). A segunda vertente de pós-humanismo seria o pós-humanismo analítico: este campo interdisciplinar contemporâneo levanta questões conceituais e éticas cruciais sobre o status humano, mas é geralmente relutante a empreender um estudo completo sobre as profundas implicações da ciência e da tecnologia para a teoria da subjetividade. Nesse sentido, há uma divisão, uma nova fragmentação entre Humanidades e Ciência (Braidotti, 2013:39). A terceira 
vertente pós-humanista seria do pós-humanismo crítico, que "propõe o sujeito no âmbito de uma eco-filosofia de múltiplos pertencimentos, como um sujeito relacional constituído na e pela multiplicidade, isto quer dizer, um sujeito que atua entre diferenças e é também internamente diferenciado, mas ainda integrado e responsável” (Braidotti, 2013:49). Em seu profundo pensamento sobre o sujeito pós-humano, Braidotti (2013:49) propõe uma recomposição do humano, um vínculo afirmativo que localiza o sujeito no fluxo de relações com múltiplos outros. É para esse sentido do pós-humanismo crítico que esta pesquisa se volta, na perspectiva de evidenciar uma das culturas do município de Palmas, reconhecendo e expressando o olhar múltiplo entre os seres humanos, meio ambiente natural e científico no qual se estamos inseridos como professores e pesquisadores.

Seguindo a metodologia pós-humana, Ferrando (2012:10-12), expõe que na teoria e na prática pós-humanista há que se considerar a produção de conhecimentos em todos os centros geográficos e intelectuais abrangendo todas as diferenças entre grupos humanos, evitando qualquer tipo de separação ou privilégios entre esses. A autora propõe uma metodologia pós-humana que sugere evitar o essencialismo hegemônico e o essencialismo resistente. Ferrando (2012:12), ao conceituar o essencialismo hegemônico, afirma: "Refiro-me ao hábito generalizado de apenas referir-se a pensadores, artistas ou teóricos que pertencem a uma hegemonia cultural" (Ferrando, 2012:13). Assim, um texto póshumano deve ser escrito por uma diversidade cultural de autores, evitando a tradicional hegemonia europeia ou americana, ou, em nosso caso, brasileira. $\mathrm{O}$ pós-humanismo pretende ouvir as vozes que produzem conhecimento, atuam, existem em nosso mundo globalizado e interconectado. Pode-se abranger mais autores que tenham uma produção acadêmica tanto quanto no circuito centroamericano-europeu, e em outros continentes. E, ainda, Ferrando destaca a necessidade de ser evitado o essencialismo resistente, no qual minorias se segmentam, separam-se cada vez mais.

Como afirmado anteriormente, pós-humanismo encontra suas raízes na desconstrução radical do "humano". Mulheres, pessoas de outras cores que não sejam brancos, gays e lésbicas, pessoas portadoras de deficiências e muitas outras pessoas de fora desafiam o discurso hegemônico pela porta dos fundos, a partir das margens [...] (Sedwick, 1990). Eles tinham que manter 
uma posição de resistência a fim de proteger a sua sobrevivência ontológica; seu esforço foi fundamental na montagem de uma genealogia de conhecimento que reconheceu e validou a sua própria existência. Como uma reação ao discurso intelectual hegemônico, e, a fím de dar espaço para vozes que de outra forma não têm nenhum, eles muitas vezes produziram relatos essencialistas, que é só para mulheres ou somente negros. (Ferrando, 2012:14-15)

Esse desmembramento dos pilares da hegemonia e da radicalidade essencialista vislumbra a inclusão e percepção do outro/Outro, que está vivendo não apenas suas culturas locais, suas formas essenciais, ou seu modus vivendi, mas precisa também estar incluído e perceptível à cultura digital que oferece oportunidades de integração. Ao pensarmos a produção de textos, de vídeos, áudios, fotografias que serão utilizadas na produção do mural poderão promover a aproximação da comunidade Kaingang de Palmas (PR) com as tecnologias audiovisuais. Tecnologias já presentes em muitas das tribos indígenas, como apontam Shohat e Stam (2006), mas que não se percebe nesta tribo específica na qual se pretende desenvolver essa pesquisa ${ }^{18}$. O pós-humanismo, como proposta de aproximação e reflexão sobre as tecnologias e seres humanos, reflete sobre esse conceito a partir da concepção de Heidegger (apud Ferrando, 2016). O conceito de tecnologia em Heidegger aproxima-se da percepção pós-humanista no sentido de não reduzi-la a um mero meio, e nem uma reificação, e sua proposição de que o homem quer dominar a técnica, mas que ela pode servir, se utilizada de modo adequado pelo homem. Para Ferrando (2016:40) “[...] Heidegger descreve a tecnologia como uma modalidade de desvelamento: "O que a essência da técnica faz com o desvelamento?” Responde-se: tudo. [...] a técnica não é simplesmente um meio. A técnica é um modo de desvelamento, porém, Heidegger lembra que a tecnologia não pode ser reduzida a uma imposição (Gestell) (Ferrando, 2016:41). Nesse sentido, propomos pensar a arte como proposta de experiência estética, cultural e filosófica, no sentido de agregar a diversidade e discutir "diversidade" como pluralidade e individualidade, pensando estabelecer ligações entre a cultura, a arte do mural como experiência estética e as tecnologias.

\footnotetext{
${ }^{18}$ Em reunião realizada com o Vice-Cacique Prof. Claudecir Viri, no dia 26/06/2018, às 10 horas, ele comentou que percebe a importância de aproximar seus alunos e sua comunidade às tecnologias, tanto como forma de comunicação entre os indígenas de Palmas, como entre outras tribos brasileiras, promovendo também maior divulgação da cultura indígena.
} 
Assim, direcionamo-nos a rever a participação desses sujeitos culturais e sociais que atuam em uma pesquisa científica com o distanciamento histórico e fragmentado entre sujeito de pesquisa e objeto de pesquisa. Por mais que houvesse interação, trocas culturais e afetivas entre esses sujeitos de pesquisa, há um distanciamento após a finalização dos projetos, um vazio que instiga a uma resposta a esta angústia de transformar não apenas o autor da pesquisa - saberes científicos, reflexões estéticas, participações em eventos científicos - mas que possa transformar e agregar um sentido, uma significação àqueles que fizeram parte dos processos de pesquisa. Nesse caminho, acreditamos que o trabalho de pesquisa junto ao Núcleo Diversitas poderia promover essa integração de sentidos entre objeto e sujeitos de pesquisa, da forma como apresentam Bairon e Lazaneo (2012: s/p): “A mudança propiciada no contexto das autorias múltiplas na produção partilhada do conhecimento apresenta uma alternativa à assimetria tradicional das representações monológicas" ao dissertarem sobre a produção de hipermídia com índios bororos, "Boé Ero Kurireu”, na qual,

[...] a produção de conhecimento questiona as estruturas rígidas e formais da produção do conhecimento científico, que elege as narrativas acadêmicas como o protagonista do Saber. "Nos antigos filmes etnográficos, por exemplo, vozes confiantes e 'científicas' falavam a 'verdade' sobre os povos nativos, impossibilitados de replicar; já as novas produções buscam uma 'prática participativa', uma 'antropologia dialógica', uma 'distância reflexiva' e uma 'filmagem interativa'." (Bairon, Lazaneo, 2012, apud Shohat, Stam, 2006: 67)

A hipermídia que os autores citam no artigo acima, é uma produção em ambiente digital que apresenta um filme de um bororo, sendo o filme montado por um xavante, e a produção de uma dissertação de mestrado de Sandro Sato. Todo o processo de construção do produto final torna-se um diálogo constante entre os participantes, no qual todos os atores produzem e ganham sentido. Essa relação nos faz lembrar a reflexão de Gadamer (1999) sobre a verdade frente à obra de arte e o jogo: aquele que joga, se lança ao encontro de algo que não é de seu domínio, que é estranho. Por ser estranho, provoca uma atitude àquele que procura familiarizar-se com esse ambiente, e após perceber que algo aconteceu, não perde sua configuração, mas alegre-se porque percebe uma transformação em si próprio, sem perder sua própria representatividade (apud Vicini, 2006:62-63). 
Essa transformação propõe-se como a descoberta de algo novo (sem afastar a tradição, como aponta Gadamer, 1999).

A Produção Partilhada do Conhecimento possui suas raízes nos Mestres Griô, uma prática ancestral africana, na qual o conhecimento se dá a partir da oralidade. Conforme a pesquisadora e criadora da Pedagogia Griô Lilian Pacheco ${ }^{19}$ (2006), sabe-se que a "sociedade africana está fundamentalmente baseada no diálogo entre indivíduos e na comunicação entre comunidades ou grupos étnicos" (Hampatebá, 1982, apud Pacheco, 2006:41) e que "os Griôs são os agentes ativos e naturais" das conversações que acontecem ao longo das gerações, neste resgate contínuo da ancestralidade (Bairon, Lazâneo; Batistella, 2010:252).

\begin{abstract}
O objetivo é que no interior das instituições científicas passemos a contar com a tradição presente no saber do Mestre Griô como interlocutora da produção de conhecimento sobre fenômenos socioculturais, alcançando e reproduzindo uma prática já indicada por Durand, ao afirmar que o cogito está no interior do ser e não o inverso (Durand, 1979b). No entanto, o desafio está no fato de encontrarmos um ambiente propício para que estes conhecimentos possam conviver, uma espécie de hipercenografia (Piault, 2000), que aja como entorno para o diálogo destas diversidades tradicionais que encontramos tanto nos modos formalização do conhecimento presentes no mundo acadêmico, quanto na organicidade do saber do Mestre Griô cultural. Não trata-se de defender uma harmonia entre diversidades discursivas, mas de propor ambientes de conversação que ofereçam um equilíbrio topológico entre intelecto e mundo sensível e que, concomitantemente, no interior das universidades, seja um interlocutor de proposições teórico-filosóficas defensoras das propriedades epistemológicas do saber do Mestre Griô cultural. (Bairon, Lazaneo, Batistella, 2010: 259230)
\end{abstract}

Dessa forma, a finalidade deste projeto enquanto inclusivismo situado será subverter a forma de produção de conhecimento, tornando aliados, pesquisador e objeto de pesquisa, como define Lazaneo, no qual “o objeto será sujeito da partilha do processo com qualquer número de participantes ou seus interlocutores" (2012:36).

Uma das preocupações conceituais desta metodologia é a definição da palavra representação, que, buscando o significado em português, ela pode

\footnotetext{
${ }^{19}$ Dossiê pedagogia Griô. Lilian Pacheco. Disponível em: http://diversitas.fflch.usp.br/sites/diversitas.fflch.usp.br/files/1.\%20PACHECO, $\% 20 \mathrm{~L} \% \mathrm{C} 3 \% \mathrm{ADlli}$ an.\%20A\%20Pedagogia\%20Gri\%C3\%B4_educa $\% \mathrm{C} 3 \% \mathrm{~A} 7 \% \mathrm{C} 3 \% \mathrm{~A} 30, \% 20$ tradi $\% \mathrm{C} 3 \% \mathrm{~A} 7 \% \mathrm{C} 3 \%$ A3o\%20oral\%20e\%20pol\%C3\%ADtica\%20da\%20diversidade_0.pdf. Acesso em 9/7/2017.
}

Iluminuras, Porto Alegre, v. 20, n. 50, p. 227-254, julho, 2019. 
significar o ato de falar ou agir em nome de outro. Como é possível falar ou agir em nome de outra cultura, sem haver um compartilhamento de ideias, principalmente quando vamos expressar, quer em palavras, escritas, pinturas, vídeos ou qualquer outro meio de comunicação? Seria uma representação dessas culturas a definição correta para o resultado final de pesquisas e audiovisuais sobre as culturas tradicionais brasileiras? Bairon e Lazaneo (2012) acreditam que o termo "apresentação" superaria o de "representação", pois, a partir de Mafesolli o termo "apresentação" 20 das coisas, que se contenta em deixar ser aquilo que é, e se empenha em fazer sobressair a riqueza, o dinamismo e a vitalidade deste mundo-aí" (Mafesoli, 1998:20 apud Bairon e Lazeneo, 2012:s/p). Refletindo sobre essa ambivalência entre representar e apresentar culturas, Bairon e Lazaneo (2012) nos provocam a olhar sobre o aspecto de produção audiovisual e hipermidiática.

\begin{abstract}
Nesse caminho, apontamos divergências conceituais e situamos os diferentes produtos no embate entre representação e apresentação a partir de realizações audiovisuais/hipermidiáticas produzidas de distintas formas de autoria: a primeira, no contexto da representação, a autoria se situa em exterioridade em relação à comunidade indígena; as segunda e terceira modalidades, no contexto da apresentação, ou o autor é um interlocutor da própria comunidade ou através de um processo de partilha do conhecimento, a hipermídia (Bairon, 2010) promove uma possibilidade de encontro entre o(s) interlocutor(es) de uma comunidade e o(s) interlocutor(es) de uma pesquisa acadêmica. (Bairon; Lazaneo, 2012:s/p)
\end{abstract}

A respeito da imagem refletida nas produções audiovisuais ou gráficas sobre as comunidades tradicionais, realizadas pelos próprios integrantes dessas comunidades, Bairon e Lazaneo (2012) citam Shohat e Stam (2006) no sentido de que uma "apresentação" realizada pelos próprios indígenas não poderia resultar em produções nas quais cada cultura somente estaria falando de si mesma, criando uma reificação ou uma simplificação do conhecimento. E acreditam que a forma partilhada e não mais unilateral, tão presente na produção de conhecimento científico, possa dialogar com os sujeitos pesquisados na forma de feedbacks e dos encontros de reflexibilidade, sempre revendo o processo de produção entre conhecimentos.

A principal metodologia de interação e produção de conhecimento nesse estudo será de Produção Partilhada de Conhecimento, que, segundo Lazaneo

\footnotetext{
${ }^{20}$ Grifo nosso.
} 
(2012), o pesquisador, numa proposta como essa, precisa sentir-se parte do grupo a ser pesquisado, e não a parte que define a trajetória da pesquisa, mas que discute junto com o grupo os passos a serem tomados na execução do projeto. No caso da produção dos vídeos de Lazaneo, ele auxiliava nas questões técnicas das câmeras de filmagem utilizadas pelos índios Bororos, Xavantes, Kuikuro e Palalos, participava dos momentos de reflexividade com a comunidade indígena, bem como das reuniões dos temas das produções, sempre como colaborador de grupo.

Da minha parte registrei fundamentalmente, aspectos em que a possibilidade "reflexiva" se mostrou propícia, qual seja, cenas em que os indígenas filmavam e por trás da câmera dialogavam sobre o registro. $\mathrm{O}$ que antes era um clássico "objeto" antropológico transformando-se em sujeito da pesquisa (Lazaneo, 2012:91).

Além dessa proposta metodológica fundada nos métodos científicos como a pesquisa bibliográfica, a pesquisa de campo precisa ser adequada aos níveis de pesquisa-ação, como propõe Lazaneo (2017) ao defender em sua tese, "Produção Partilhada e Reticularidade fílmica", que a produção partilhada do conhecimento possui estreita relação com a pesquisa-ação, pois uma das características desse método de pesquisa é a estreita relação entre pesquisador e o grupo a ser pesquisado e a complexidade de caminhos que esse tipo de encaminhamento metodológico pode suscitar.

Segundo Baldissera (2001:13), na metodologia de trabalho de uma pesquisa-ação "é importante utilizar todos os tipos de registro: diário de campo, fotografias, filmagem e a ficha de descoberta, que é usada para sistematizar a observação da realidade em seus diversos níveis, histórico, genético, morfológico, social, relacional entre outros".

Uma vez que a pesquisa será realizada com a comunidade indígena Kaingang (Palmas, PR), serão organizados encontros semanais para se estabelecer os temas que forem indicados pela comunidade indígena como relevantes de sua cultura. Nessas interconexões culturais, as vozes serão múltiplas, e será preciso haver uma documentação que possa registrar essas conversas. Posteriormente ao levantamento dos aspectos culturais que o grupo definir como relevantes para a produção das imagens do mural, possivelmente terão início as oficinas de pintura por parte da pesquisadora e as oficinas de arte indígena por parte dos Kaingang de Palmas. Nessas oficinas de pintura, será abordado o tema mural e suas técnicas, 
sendo que para as oficinas ministradas pelos indígenas será definido por eles mesmos de que maneira serão conduzidas, até chegar-se à produção do mural real e ou virtual, que será avaliado no decorrer do desenvolvimento da pesquisa de forma compartilhada entre os sujeitos da pesquisa.

\section{Referências}

ANJOS, Moacir dos. Local/global: arte em trânsito. Rio de Janeiro: Jorge Zahar Editora, 2005.

ARGAN, Giulio. Arte Moderna. Companhia das Letras: São Paulo, 2005.

ART of Conflict. 2012 • Documentário • 1h 13m. Este filme mostra o impacto, a função e o futuro dos murais na Irlanda do Norte, uma expressão dos violentos problemas da região. Data de lançamento: 12 de outubro de 2012 (mundial). Direção: Valeri Vaughn. Produção: Vince Vaughn, Netflix. Disponível em: https://www.netflix.com/watch/70267850?trackId $=13752289 \&$ tctx $=0 \% 2 \mathrm{C} 1 \% 2 \mathrm{Ce}$ cad8c91e951a7a21f004595fc70a8c1345079a2\%3Ac4a5b3e7b97a68b91de909350 0d106dc1f890829. Acesso em 20/03/2017.

BAIRON, Sergio; LAZANEO, Caio. Produção partilhada do conhecimento: do filme à hipermídia. Artigo publicado nos Anais do Intercom - Sociedade Brasileira de Estudos Interdisciplinares da Comunicação. XXXV Congresso Brasileiro de Ciências da Comunicação - Fortaleza, 2012.

BAIRON, Sergio; BATTISTELA, Roberta Naavs; LAZANEO, Caio. Fundamentos da Produção Partilhada do Conhecimento e o saber do Mestre Griô. Disponível em: file://D:/Users/User/Downloads/113894-206494-1-SM.pdf. Acesso em 3/7/2017.

BALDISSERA, Adelina. Pesquisa-ação: uma metodologia do "conhecer" e do "agir" coletivo. Sociedade em Debate, Pelotas, 7(2):5-25, Agosto/2001. Disponível em: http://revistas.ucpel.edu.br/index.php/rsd/article/viewFile/570/510. Acesso em maio/2018.

BELL, Julian. Uma nova história da arte. Trad. Roger Maioli. São Paulo: Martins Fontes, 2008.

BELUZZO, Ana Maria de Moraes. O Brasil dos viajantes. Editora Objetiva: Rio de Janeiro, 1994.

BRAIDOTTI, Rosi. Diferença, Diversidade e Subjetividade Nômade. Tradução: Roberta Barbosa. labrys, estudos feministas. Número 1-2, julho/ dezembro 2002. http://www. unb. br/ih/his/gefem. 
. The Posthuman. Polity Press: Cambridge, EUA. Edição do Kindle, 2013.

CANCLINI, Néstor García. Culturas híbridas: estratégias para entrar e sair da modernidade; tradução Helóisa Pezza Cintrão, Ana Regina Lessa. E. ed. E. reimpr. São Paulo: Editora da Universidade de São Paulo, 2008.

. A socialização da arte: teoria e prática na América Latina. São Paulo: editora Cultrix, s/d.

CASTRO, Eduardo Viveiros de. Metafísicas Canibais. São Paulo, Cosac \& Naif, 2015.

CERTEAU, Michel. A cultura no plural. São Paulo: Papirus Editora, 1995.

DEWEY, John. Arte como experiência. Coleção os Pensadores. São Paulo: Abril Cultural, 1980.

ECO DE LA MONTANA. Dirección Nicolás Echevarria. México, 2014. Disponível em: Netflix. Acesso em: 15/06/2017.

FERRANDO, Francesca. Il postumanesimo filosófico e le sue alteritá. Pisa (Itália): Edizioni ETS, 2016.

NB. Dall'11 al 14 Settembre 2013 si terrá la $5^{\circ}$ Conferenza Internazionale del Postumanesimo presso l'Universitá di Roma Tre, dal titolo: The Posthuman: Differences, Embodiments, Performativity. Call For Papers: TBA. L'EVIDENZIATORE. Site Academia.edu. Disponível em: file://D:/Users/User/Downloads/POSTUMANESIMO_ALTERITA_E_DIFFERE NZE.pdf. Acesso em outubro/2016.

Toward a posthumanist methodology: a statement. Disponível em: https://www.academia.edu/1243762/TOWARDS A POSTHUMANIST METH ODOLOGY A Statement. Acesso em fevereiro de 2014.

GADAMER, Hans-Georg. Verdade e Método - Traços Fundamentais de uma Hermenêutica Filosófica. Tradução de Flávio Paulo Meurer. Petrópolis, RJ: Ed. Vozes, 1999.

HEIDEGGER, Martin. A origem da obra de arte. Tradução de Maria da Conceição. Lisboa: Costa Edições 70, Portugal, 2000.

HALL, Stuart. A identidade cultural na pós-modernidade. Tradução: Tomaz Tadeu da Silva, Guaracira Lopes Louro. 10 ed. Rio de Janeiro: DP\&A, 2005.

KOBRA, Eduardo. Site do artista Eduardo Kobra. Disponível em: http://eduardokobra.com/. Acesso em 5/5/2017.

KUONI, Carin. Joseph Beuys in america. New York, EUA: Ed. Four Walls Eight Windows, 1993. 
LAZANEO, Caio de Salvi. Produção partilhada do conhecimento: uma experiência com as comunidades indígenas Xavante e Karajás. Dissertação de Mestrado - Diversitas - USP, 2012.

. Produção partilhada e reticularidade filmica. Tese de DoutoradoDiversitas - USP, 2017.

PRÁCTIQUES MURAL CONTEMPORÁNIES. Fundació Joan Miró. Impressío: Nova Era, S.A., Barcelona, 2010.

SHOHAT, Ella; STAM, Robert. Crítica da imagem eurocêntrica: multiculturalismo e representação. São Paulo: Cosac \& Naif, s/d.

SORGNER, Stefan Lorenz; RANISCH, Robert (Org.). Post- and Transhumanism: na introduction. Frankfurt am Main: Peter Lang, 2014.

VICINI, Magda Salete. Arte de Joseph Beuys: pedagogia e hipermídia. Ed. Mackenzie: São Paulo, 2006.

Dimensões Comunicacionais no conceito de escultura social de Joseph Beuys: um processo de tradução criativa. Tese de Doutorado. Pontifícia Universidade Católica, São Paulo, 2011.

Recebido 01/07/2019

Aprovado 24/07/2019 